\title{
An Empirical Study of Big Data Analytics in Rural Arena
}

\author{
Vasantha Gouri ${ }^{1} \&$ Mohsin Uddin ${ }^{2}$ \\ ${ }^{1}$ Faculty at National Institute of Rural Development and Panchayati Raj, Hyderabad, India \\ ${ }^{2}$ Tishk International University, Erbil, Iraq \\ Correspondence: Mohsin Uddin, Tishk International University, Erbil, Iraq. \\ Email: uddin.mohsin@gmail.com
}

Received: January 12, 2019

Accepted: February 22, 2019

Online Published: March 1, 2019

doi: 10.23918/ijsses.v5i3p192

\begin{abstract}
Innovations in ICT sector facilitate qualitative life style for citizens in the globe. Countries that facilitate usage of new techniques in ICT, i.e. Big data analytics, find it easier to fulfil the needs of their citizens. Big data is characterized by its volume, variety, and speed. Analytics involves its processing in a cost effective way in order to draw conclusion for their useful application. Big data also involves the field of machine learning, artificial intelligence leading to accuracy in data presentation useful for public policy making. Hence using data analytics in public policy- making is a proper way to march towards all round development of any country. The data-driven insights can help the government to take important strategic decisions with regard to socio-economic development of country. Developed nations like the UK and the USA are already far ahead on the path of digitization with the support of Big Data analytics. India is a huge country and it is currently on the path of massive digitization being realised through Digital India Mission. Internet connection per household is on the rise every year. This transforms into a massive data set that has the potential to improvise the public services delivery system into an effective service mechanism for Indian citizens. In fact, when compared to developed nations, this capacity is being underutilized in India. This is particularly true for administrative system in rural areas. The present paper focuses on the need of the adaptation for Big data analytics in Indian rural administration and its contribution towards development of the country on a faster pace. Results of the research focused on the need for increasing awareness and serious capacity building of the government personnel working for rural development with regard to Big data analytics and its utility for development of the country. Multiple public policies are framed and implemented for rural development yet, the results are not as effective as they should be. Big data has a major role to play in this context as it can assist in improving both policymaking and implementation, which aims at all round development of the country.
\end{abstract}

Keywords: Digital India Mission, Public Service Delivery System, Public Policy, Indian Administration

\section{Introduction}

With advancement in computer technology and growing digitization of services, citizens are benefited with quality services all over the world. However, large electronic data are being generated in the process of digitization of public services. Smart phones, video recordings, smart phone applications like WhatsApp, Facebook, Twitter and so on. Connecting to internet produces huge amount of data. Development of Big data set in this context, relates to innovative methods of collecting, storing and processing information to increase its availability and usability. Big data is the term that describes the large volume of data both structured and unstructured that influences an organizationon a day-to-day basis. Big data can be analysed for insights that lead to strategic decisions making in the organizations. 
Gathering and storing information is through an age-old concept, the concept of Big data is relatively new, gained popularity only in early 2000s when industry analyst Doug Laney framed the present definition of Big data as three Vs:

1 Volume: Data are collected from a variety of sources-business transactions, social media, mobile data and information from sensors and so on. Storing data was a challenge in the past but new technologies have reduced this burden

2 Velocity. Data keep on multiplying with extreme speed and hence must be dealt in timely manner. Sensors, login machines in the offices all drive in the need to deal with large volume of data in limited time

3 Variety: Data are found in different types and formats from structured, numeric data to unstructured text documents like email, audio, smart messages (SAS, 2018)

The other two dimensions identified are variability and complexity as the data accumulated are found to be more diverse and complex in nature.

\section{Importance of Big Data}

Organizations are under continuous pressure to perform better and deliver services on a variety of frontscost cutting, time management, new product development and smart decision-making. With the help of Big data combined with high powered analytics, root cause for serious failures in an organization can be detected, also within minutes, entire risk portfolios can be recalculated and detect the fraudulent behaviors that effect the whole organization. While $90 \%$ of the digital information worldwide has been created over the last two years, improvement in processing of data was only 40\% between 2010 and 16; storage of data capacity is going down by 500\% (SAS, 2018). This is because of the huge volume of data produced all the time. Several reputed organizations; American Express, Netflix, Google etc. currently find Big data to be most effective way of handling large number of customer transactions within limited time (Economic Times, 2017).

Advancements in computing technology make large data available to Government, which can cost effectively utilize it in delivering social services and bring about improvement in social development indices. However the real revolution is not machines that calculated data but in data itself, and how we use it (Mayer-Schönberger, 2013).

Big data can be used for organizations in the following way:

a) Cost Saving

b) Availability of data on time

c) Protect online reputation of the organization

d) Know your customers better.

Government organizations in countries across the world utilize the Big data services to monitor the health and safety of its citizens at the same time maintain a vibrant economy that could bridge the difference between haves and have not's. Big data if properly utilized brings astonishing positive outcomes for public administration in terms of its efficiency and overall client satisfaction. Digitization 
of information and related data flexibility, progress in artificial intelligence \&automation all these lead to novel and powerful methods for accessing and using information in new ways hitherto not available.

\section{Application of Big Data in Organizations across the World}

Public administration in several rich countries have adopted Big data strategies or policies like the Australian Government Information Management office 2013, UK Department of Business innovation and skills, 2013, US executive office of President 2014. Big data is utilized for public supervisionidentifying the irregularities and taking responsive action. US Department of Energy used Big data methods to improve solar and wind forecasts and improve the assessment of renewable energy sources in the US energy system. In Maryland (USA) Big data methods support a performance based approach linking the data about public tasks and authority's activities. It was possible to shift form input centric approach to an output that measures output and outcomes. Maryland authorities also share information on obtained outputs and outcomes via internet (Maciejewski, 2016). In all the above examples, Big data and methods for their use are an emerging phenomenon in management landscape which brings very good results in terms of efficiency.

\section{Big Data in Developing Countries}

All the developing countries commonly face the problem of poverty and its effects on citizens. Hence Big data is introduced in these countries to tackle poverty related challenges. For example countries like Kenya and India are gathering data related to weather patterns, using models to forecast climate variations which can help farmers to adapt right agricultural practices, boost crop yields and tackle hunger (Bhalla, 2017). Through geo locating, a rural African farmer working in his farm can with the help of an application installed in his cell phone, identify the soil type, needs of the field and seek advice regarding appropriate seeds, where they can be purchased and how they can be planted and harvested. A retrospective analysis of 2010 Cholera outbreak in Haiti showed that mining data from Twitter and online news reports could have given the country's health officials an accurate indication of disease spread with a lead time of two weeks (Kshetri, 2014). Burundi- the world's most resource constrained countries, has constantly poor health outcomes. Development informatics team of USAID's Global development lab and FHI 360' together launched a research project to clarify the value of open data initiatives in developing countries. As a part of Big data initiative, Result based financing (RBF) was introduced in health sector at Burundi. RBF is an instrument that links development financing with predetermined results. The data is made available for funding organizations, ministry of health, medical practitioners and policy makers for assessment purpose (Farahi, 2017). Scientists studying the pattern of Malaria in Kenya, made efforts to pinpoint hotspots where disease transmissions were taking place by guiding the eradication efforts (Brindley, 2013).

Thus Big data in the context of development helps us to gain a better understanding on the nature of poverty and design appropriate policies to wipe it out at the earliest possible. Infact there is a dire need for usage of Big data initiatives in developing countries but are constrained by lack of investment in purchasing infrastructure required for adopting Big data on a large scale. 


\section{Big Data in India}

India is already moving ahead with leaps and bounds in the field of Information Technology and witnessed implementation of Big data across industries such as public health finance, banking and FMCG. Big data industry currently employs 90 thousand people across various sectors and such a growth is propelled by demand for cloud based solutions and predictive analytics capabilities. With around 600 companies in this field, 400 being start-ups, a hundred were added in 2015 alone. Though at present, America based IT firms have become world popular, soon Indian companies are expected to take over and come up with sophisticated data solutions. Currently Reliance JIO is also using Big data to expand her market. Non-profit agencies like Akshayapatra foundation is also using Big data analytics to deliver food to schools in cost effective manner. In fact the largest entrant in this field of Big data Reliance Jio termed data as 'the oxygen of the digital era'.NASSCOM anticipated, India's Big data industry will capture $32 \%$ of global market to reach 16 billion dollars by 2025 from the current level of 2 billion dollars (Patel, 2017).

India is currently one of the top ten BDAAS (Big data as a service provider) markets in the world and is expected to rise further by 2025. BDAAS market is at present under pressure to satisfy increased demand for predictive analytics and cloud based solutions for all organizational concerns (Bhattacharya, 2017). DST (Department of Science and Technology) under the ministry of Science and technology and earth sciences has been given the task to develop Big data analytics and encourage its usage in the government sector. National Data Sharing and Accessibility policy (NDSAP) 2012 of DST is designed to promote data sharing and enable all citizens to access government owned data. Further, Big data analytics and infrastructure development in India is being steered by C-DAC, Centre for development of advanced computing, Ministry of Electronics and IT. C-DAC in India regulates and controls training on Hadoop for Big Data Analytics and Analytics using Apache spark for various agencies including defense (Singh, 2017).

Digital India Programme: Government of India (GOI) has taken initiative to digitize India by enabling Internet access available to over 2 lakh villages by 2019, promoting ie-governance, e-banking and similar others to lead India into a knowledge based society. One of the digital India initiative 'Aadhaar 'provided to every citizen of India, is considered to be one of the largest ID programme in the world. As a part of this programme, Biometric data of each citizen is captured and used for all necessary purposes like voter ID, Passport verification and latest this ID is used for issuing cooking gas facilities to the poor on subsidized rates across the country (Roy, 2017).

In another initiative 'Digi Locker 'provides a personal storage space in the cloud to the citizens in India. Organizations registered with digi locker can directly send e-copies of documents and certificates to the concerned citizen's locker. Further using e-sign facility citizens can upload scanned copies of their legacy documents into their accounts from digi locker. Up to 2015 Feb over 825000 users have registered to use the digi lockers with over 1.5 million documents being uploaded. Further as a process of demonetization, two dominant currency notes were devalued and banned to prevent the illegal financial transaction like fake currency, black money that corrupt the Indian economy. Next, as a part of digitalization, data on each transaction is stored facilitating increased foreign investment and leading to economic growth (Roy, 2017). 
Apart from optimizing private businesses and public goods \& services, NITI AYOG adopted multiple methods to increase Big data usage in India; for example utilizing Big data in incorporating skill and human resource development (Patel, 2017).

\section{Big Data Applications}

Knowledge of Big data is applied in crucial sectors in the country as a part of governance today. Some of them are as follows:

Big Data in health care: Huge data is generated by hospitals, primary health centres, health insurance companies and other state and central government agencies. Fortunately, Big data has brought a welcome shift in the health care sector. Today, Health care analytics is not just limited to - reduce the cost of health care facilities - diagnosis, treatment and medication. Big data Analytics in this area can also contribute to predicting the outbreak of epidemic and endemic diseases like SAARS and Flu (Analytics India, 2017). Predictive Policing (Crime and Criminal Network Tracking System - CCTNS) seeks to use Big Data for better provision of citizen centric services, connect about 14000 police stations across the country and facilitate investigation, detention and prevention of crime. This is a useful method for Indian Police as it aids in effective disposal of criminal cases as well as law and order control. However there is a scope for misuse as it could lead to warrantless arrest and detention without any probable cause (Elonnani, 2017).

UID: Aadhaar is already having one billion registrations. It is an online digital and paperless identity system which can act as a platform for a number of digital services all of which produces enough data precious to both government and private sector. In future, this digital identity system helps in identifying people reducing fraud and facilitating efficient delivery of services to the public. Based on UID there is digital identity system which collects and stores information throughout the lifecycle of the individual. As a result a database of the individual is built which when combined as enabled by the seeding process will provide 360 degrees identification (Elonnani, 2017).

Big data enabled credit scoring: One of the key areas of focus in Digital India mission is the use of mobile and e-banking technology to enable greater financial inclusion for the poor. Mobile and ebanking technology is a part of larger shift that is happening in the banking sector whereby companies are utilizing technology to provide financial services often through new business models and platforms. Prominent business areas in the Finetech sector in India include credit scoring, lending payments, brokerage and insurance. Big data enabled credit scoring helps the company to identify the consumer ability to repay. With advancement in the fields like Artificial intelligence \& Deep learning algothrims the next phase of growth for Big data industry in India is clearly visible (Elonnani, 2017).

\section{Big Data in Indian Rural Administration}

Rural areas make a significant contribution to economic development in India through Agriculture, small scale and cottage industries. Focus of government to build Digital India through broadband highways connecting every household, village Panchayat and government department generate huge amount of data. By analyzing it with the help of Big data, solutions to the never-ending rural problems can be found 
(Dalai, 2015).

Further, there are several advantages of Big data application noticed in Indian settings (Elonnai, 2014):

1. Financial inclusion: Access to alternate data can enable the provision of credit to a number of people ignored by the banks which generally use a different set of data points for evaluating whether or not a loan can be given and bring them within the credit system

2. Substantial opportunity for private sector: Big data enabled credit scoring present a 4 to 5 billion USD opportunity for the private sector. This will generate more jobs and revenue, which contributes to GDP of the country.

3. Data Driven efficiency: Credit underwriting using Big data has access to a far greater volume of data. This could lead to better underwriting and credit scoring

4. Ease of doing business: There is a possibility of getting loan approvals in a matter of hours or days as against weeks and months in the presence of various competing companies.

5. Personalized services: More granular data can enable firms to create more personalised portfolios for their clients which would be more beneficial for lenders as well as borrowers.

However, adoption of Big data to standardize or improve its efficiency is done by very few institutions in the country. There are several reasons for this situation. Vast difference is noticed in the work methods of public and private sectors in any country. Just as theoretical insights differ, the use of technologies and tools also differ between public and private organizations. In fact Big data initiatives in public sector organizations are generally underutilized and the value returned is less than expected. Conflicting goals, changing leadership, stewardship of values and challenges in measuring the outcomes are all thought to constrain the use of Big data application in public sector organizations (Chegus, 2017). Big data technology in India is currently facing many challenges like inadequate storage, no clarity on application of Big data and its scope of continuation (Aggarwal, 2017).

There is lack of data collection and management infrastructure particularly in the developing world. Most of the Big data in the developing countries including India is essentially a digital accumulation of a very specific type of mobile phone call data records. Though analyzing these records have shown utility, there are inherent challenges in accessing these records. There is absence of institutional mechanism to set right the data and make use of it in a meaningful way. Currently there is no co-ordination in data management practices in various ministries and Government departments in India and this leads to multiple data sets and confusion (Aggarwal, 2017). Absence of infrastructure to support privacy, preserving data is useless wherein the researchers do not need access to raw data. Further, privacy and anonymity are intimately linked and are two sides of the same coin. Lack of data integrity is a major challenge to the reproducibility and applicability of data. Further utilizing internet without knowledge about Big data can pose a serious threat to a nation's cyber security and is a barrier to its socio economic development. Hence, Government needs to come up with a nationwide data management policy (Aggarwal, 2017).

\section{Literature Review}

The following literature study was done to find out the extent of Big data utilization in India: Kulkarni (2016) has explored, reached and practiced specific aspects of data mining and machine learning. As per 
the authors, Big data is all about large sized unstructured data and elegance to deal with them. Authors focus on Big data with traditional data mining. The book elaborates relationship between text analysis and Big data with reference to practical problems and research carried out in this area.

In his report Richter (2017) illustrates how the BWSSB-IBM approach narrows down the complex field of water provision to a question of water in and outflow measurements and monitoring of BWSSB ground personnel. IBM in alliance with Bangalore water supply and sewage board is implementing a water flow sensor network and geographic data base system under the label of Big data for water supply. With the advent of better data collection technology capturing the processing market \& business, data will be more efficient which would lead to construction of timely and better decision support models from diagnostic to somewhere closer to predictive /prescriptive (Banarjee et al., 2013). In India, analytics and Big data industry together is sized around 10 billion and is expected to grow beyond 26 billion after 2017. Further it is being forecasted that market for analytics and business intelligence platforms will be the fastest growing segments in the software market.

Kshetri (2014) presents a comprehensive review of academic literature on policy documents fromgovernment organizations and international agencies, reports from industries and popular media, on trends in Big data utilization in Big corporations as well as other activities in industrialized countries. Author opines that Big data is likely to help better utilize the scarce resources and can deal with various sources of inefficiency that are key obstacles for development process.

Big data has become a recent area of strategic investment for IT organizations. For example the rise in mobile users has increased enterprise aggregation of user statistics. Much of the data gathered in real life provides unique and powerful opportunity if analysed and acted upon. Big data represents the changing world we live in. The more the things change, the more the changes are captured and recorded as data. Further, the author discusses about the best practices in implementing Big data and data science for analytics. Organizations today need analytical expertise as well as understanding of data sciences and algorithmic approaches that provide data analytics to them. Organizations today need clarity offered by Big data and data sciences to support their mission focused programmes (Sriramaraju, 2017).

Rani (2018) opines that, ever-growing data provides a tidal wave of opportunities and challenges in terms of data capture, storage manipulation, knowledge extraction, security, privacy and visualization. In recent years there is a huge surge in the academia over better understanding of Big data. Author through this article throws light on Big data evolution, open source Big data stream processing frameworks and prevalent research challenges in the way of realizing true potential of Big data. Reddy (2014) throws light on different platforms available for performing Big data analytics. Big data is in fact driving radical changes in traditional data analysis platforms. Author assesses and analyses the advantages and drawbacks of each of these platforms based on various matrix such as scalability, data I/0 rate, fault tolerance, real time processing, data size supported and iterative task support. All these can potentially aid the readers to choose the correct platform for Big Data usage.

Moorthy et al. (2015) clearly advocates that need of the hour is people who can make sense out of data gathered and not the strategic marketing planners who plan how to gather data. Big data analytics are 
changing the way organizations are taking decisions. From traditional business intelligence and analytics, the world is changing more towards predictive analytics and Big data centric business decision models. Majumdar et al. (2017) focuses on the importance of Big data applications in agriculture. In order to have accurate yield estimation for numerous crops, data mining techniques are necessary tools. Big data thus became more relevant for agriculture. Providing information about soil variety, weather conditions, agricultural inputs being used and market prices make Big data all the more relevant to farmer. Through this study, authors focus on analysis of agriculture data and find optimal parameters to maximize crop production using data mining techniques and multiple linear programming. Jain et al. (2018) throws light on the privacy of data aspect in this article. Since Big data has become a part and parcel of everyday life, privacy has become a topic requiring emphasis. Privacy of data can be achieved through various means but the authors here focus on differential privacy. Fundamental ideas about sensitivity and privacy budget, the composition properties, the ways through which they can be achieved are updated. However, differential privacy is still an area requiring in-depth research.

Problem Statement: Based on the above literature on Big data usage and its progress in India problem identified was to find out the extent of Big data usage in Indian rural administrative system dealing with rural development activities.

\section{Objectives}

The following objectives were framed accordingly:

- To find out the extent of awareness among the rural government organizations regarding Big data.

- To know about the purpose for which Big data is being used by government agencies in rural areas currently.

- To find out the need for capacity building to use Big Data on a large scale in rural development.

\section{Research Methodology}

Since there is a need to find out the extent of Big data usage in government institutions all over the country, a sample of 54 respondents who were participants of two National Conferences were considered for the study. First one was regarding 'ICT Applications in Rural Development' held in NIRDPR on Aug $6^{\text {th }}$ to $10^{\text {th }} 2018$. This was a training programme held for the participants working in government organizations involved in rural development all over the country. The second national workshop was held at Osmania University regarding Updating knowledge about Big data, machine learning and Python usage from $12^{\text {th }}$ to $15^{\text {th }}$ August 2018. Participants here were academicians involved in teaching and research in Statistics hailing from rural areas all over the country. Thus sample of respondents contained academicians, officers involved in public policy making and implementation as well. For the sake of better result analysis they were categorized as High level officers, middle level officers, ground level officers and academicians.

Tool for research: Based on the objectives mentioned above, questionnaire was administered on the sample of participants to find out their involvement with Big Data analytics. 


\section{Result Analysis}

Responses to the questionnaire administered on the sample of participants was analysed on SPSS and the following observations were made.

Awareness about Big data:

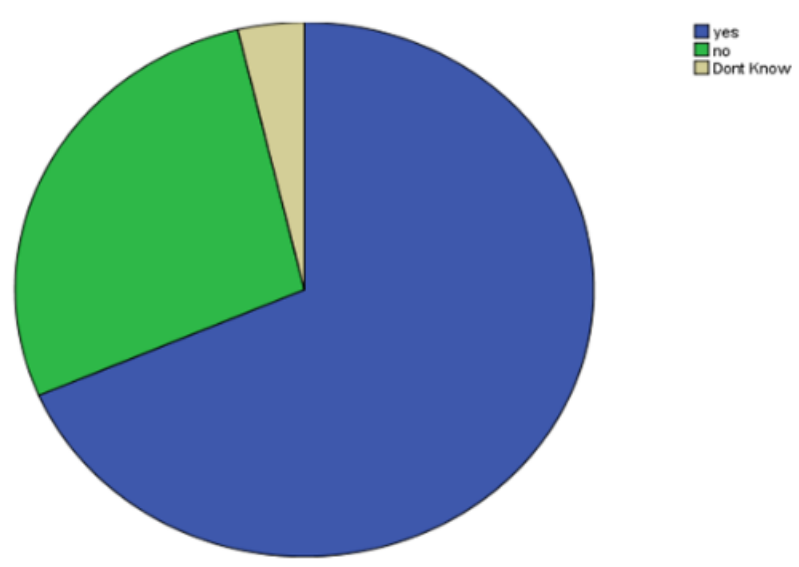

Figure1: Percentage of awareness about Big data

From the above figure it can be inferred that $68.5 \%$ of the respondents are aware about Big Data and $27 \%$ do not know anything about it and 3.7\% partially know about it. Among the respondents, it was also found that Faculty was more aware about Big data.

Usage of Big data in Rural Administration: Big data is not being frequently used in the government sector despite being aware of its advantages. $74 \%$ of the respondents replied that Big Data is not being used in their organizations. This was evident from the following table.

Table 1: Big Data being used/not used

\begin{tabular}{|c|c|}
\hline Response & Percent \\
\hline Yes & 25.9 \\
\hline No & 74.1 \\
\hline Total & 100.0 \\
\hline
\end{tabular}

The corresponding bar chart figure 2 indicates that Big data is being used more at policy making level by the high level officers and next at policy implementation stage by the ground level officers. 

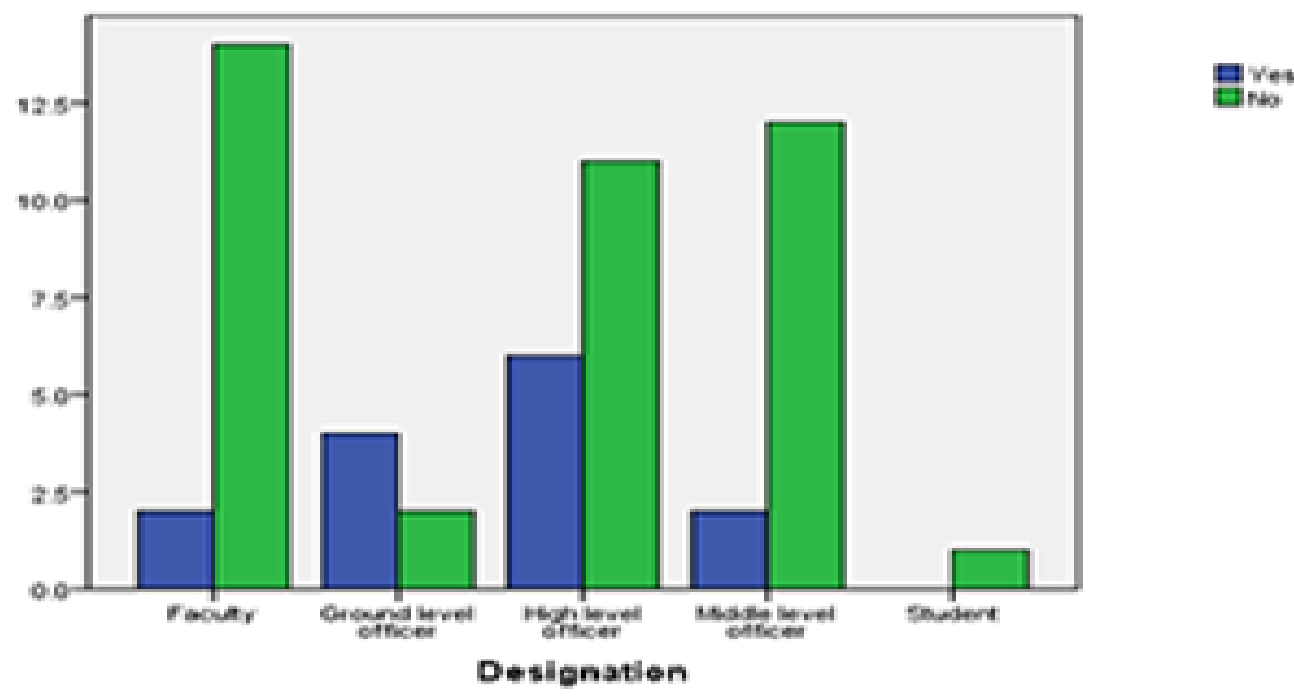

Figure 2: Indicating Big data usage at different levels in rural government sector

Year, Big data usage was introduced: Effort was made to find out since when approximately the Big data is being used by the respondents in their respective organizations. $11 \%$ of the respondents informed that Big data was being used in their organizations, very recently from 2015 onwards. Next, an effort was made to find out the need for capacity building of the government officials to equip them in using Big data effectively.

Need for capacity building: From Table 2 it can be inferred that majority of the respondents' i.e $48 \%$ are aware about the fact that Big data can reduce their work burden. However, 37\% do not find it to be so useful and 14\% did not respond. This clearly indicates the need to improve awareness among the government officials and faculty regarding Big data analytics and its usages. In addition, effective usage of Big data requires perfect training to the employees. Hence, effort was made to find out if any training was already imparted to them and if not would they like to be trained in this aspect.

Table 2: Opinion of respondents on Big data usage

\begin{tabular}{|c|c|}
\hline Opinion & Percent \\
\hline Positive & 48.1 \\
\hline Negative & 37.0 \\
\hline No reply & 14.8 \\
\hline Total & 100.0 \\
\hline
\end{tabular}

The following figure indicates the extent of training received by the respondents so far with regard to Big data usage; 


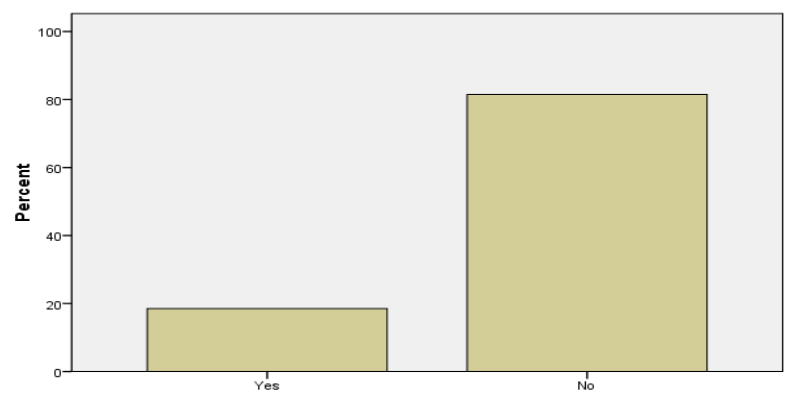

Figure 3: Indicating training received by the respondents

From the above figure and Table 3 below it can be interpreted that government officials or faculty are not sufficiently trained in using Big data also almost $77 \%$ of them are looking forward for essential training. There is a clear need to train the sample respondents and government officials by and large, enabling them to utilized Big data analysis both at policy making and implementation stage. Capacity building is the need of the hour for all those involved in government

Table 3: Need for training

\begin{tabular}{|c|c|}
\hline Response & Percentage \\
\hline Yes & 77.8 \\
\hline No & 22.2 \\
\hline Total & 100 \\
\hline
\end{tabular}

With regard to the difficulties faced in using Big data the following analysis was made in Table 4. The table clearly indicates that more than half of the respondents $(53.7 \%)$ did not work with Big data at all and the remaining those who used Big data faced certain hurdles like difficulty in compiling the data (20.4\%), difficulty in analysing the data (13\%) and the remaining with other difficulties like limited network connection \&limited access to data.

Table 4: Difficulties faced in using Big data by respondents

\begin{tabular}{|l|c|}
\hline Response & Percent \\
\hline Difficulty in compiling the relevant data & 20.4 \\
\hline Difficulty in analysing data & 13.0 \\
\hline Any other difficulty & 13.0 \\
\hline Not worked with Big Data & 53.7 \\
\hline Total & 100.0 \\
\hline
\end{tabular}

Purpose for which Big data is being used in rural areas:

As a response to the question for what purpose Big data is being used in their respective organizations 
the answers of respondents hailing from different places in the country were tabulated as follows in Table 5. This particular table projects on the different purposes for which Big data analytics is being utilized under different public policies on rural development and policy implementation agencies in the country.

Table 5: Big data currently used in different rural government organizations for Public policies making/implementation in India

\begin{tabular}{|c|c|}
\hline Work places of the Respondents & Purpose \\
\hline Rurban Mission Haryana & $\begin{array}{l}\text { Big data is being used for analysing beneficiaries of } \\
\text { RURBAN Public policy }\end{array}$ \\
\hline $\begin{array}{l}\text { District } \\
\text { Rural Development } \\
\text { Agency,Ambala,Haryana }\end{array}$ & $\begin{array}{l}\text { For data collection and analysis regarding the } \\
\text { beneficiaries of different Government schemes }\end{array}$ \\
\hline $\begin{array}{l}\text { Forest and Climate Change Department, } \\
\text { Jarkhand }\end{array}$ & $\begin{array}{c}\text { Used it for online gathering of forest information and } \\
\text { related Activities }\end{array}$ \\
\hline Jharkhand Forest Department & $\begin{array}{l}\text { Forest Management } \\
\end{array}$ \\
\hline Prime Minister Awaas Yojana (PMAY) & $\begin{array}{c}\text { To Monitor the project and reporting the project } \\
\text { progress }\end{array}$ \\
\hline Orissa State Rural Development office & $\begin{array}{l}\text { Big data is being used for getting information and } \\
\text { accurate answers for queries }\end{array}$ \\
\hline Irrigation department Sirsa, Haryana & For compiling Micro Irrigation Data \\
\hline $\begin{array}{l}\text { Agriculture \&RuralDevelopment, Madhya } \\
\text { Pradesh }\end{array}$ & Monitoring Agriculture Schemes and result analysis \\
\hline $\begin{array}{l}\text { Mahatma Gandhi National Rural } \\
\text { Employment Guarantee scheme, Punjab }\end{array}$ & $\begin{array}{l}\text { Big data is being used for preparing the reports and } \\
\text { monitoring the reports of MGNREGA works }\end{array}$ \\
\hline Directorate of school education, Karnataka & $\begin{array}{l}\text { To analyse the school students achievement in their } \\
\text { academics }\end{array}$ \\
\hline $\begin{array}{l}\text { Kasturbagandhi Post Graduate College, } \\
\text { Secunderabad }\end{array}$ & $\begin{array}{l}\text { Big Data is being used for skill enhancement course } \\
\text { for Bsc Final year students in Statistics }\end{array}$ \\
\hline $\begin{array}{l}\text { Millionwalls communications ltd } \\
\text { Kompally, near Hyderabad }\end{array}$ & $\begin{array}{c}\text { Big data is used to identify disease prediction models } \\
\text { in Agriculture }\end{array}$ \\
\hline
\end{tabular}

Big data used in other organizations as per the knowledge of the respondents:

Responses to the question whether Big data analytics is being used in organizations other than the respondents presently working are tabulated as follows in Table 6 . This table gives us an insight into the various different activities for which Big data is being utilized apart from public policies and development activities. 
Table 6: Big data used in different sectors in India

\begin{tabular}{|c|c|}
\hline S1 No & $\begin{array}{c}\text { Purpose for which Big data being used in other } \\
\text { organizations }\end{array}$ \\
\hline 1 & $\begin{array}{c}\text { Using mobile apps, social websites and e-commerce } \\
\text { sites }\end{array}$ \\
\hline 2 & private organizations like Accenture, Bank of America \\
\hline 3 & Data Analysing in corporate hospitals \\
\hline 4 & Big data is used in GIS and managing database \\
\hline 5 & Useful to analyse the progress of public policies \\
\hline 6 & Commonly used in IT Sector \\
\hline 7 & Big data is being used in Health sector and shopping \\
malls
\end{tabular}

From the above table it can be inferred that Big data and its utility is known to people of India working in government sector. However, lack of infrastructure and financial support and other related hindrances discourage them from adopting Big data analytics as a part of their routine operations.

\section{Conclusion and Suggestion}

Big data can be used as a powerful tool in Public Administration of a country. This is more relevant for administering the rural part of the country. In all the developing nations, India in particular, do have rural areas far flung from the government, lacking in basic amenities and data access as well. According to the 2011 census of India, there are 640,867 different villages in the country. Huge data is available with local governments relating to multiple villages within their jurisdiction. This data however, needs to be streamlined for efficient administration of Rural India and addressing the rural social issues and thus Big data has a major role to play in rural development. Predicting the weather conditions, soil salinity and fertility, suggesting suitable crop to be grown in particular soil, marketing of the produce, customer preference identification - Big data can be utilized promptly.

Suggestions: Based on the above study the following suggestions are made indicating simple and innovative techniques that can provide improved utility of Big data analytics in rural development and thereby pave the way for better governance of rural areas in the country.

- With the growing volume of data in Government departments like Panchayati Raj data analysing can be made easy through Big data

- Since Panchayati Raj \&Rural Development (P\&RD) ministry generates huge amount of data, Big data would be helpful in planning and evaluation of the schemes and other activities framed for rural development

- There is a need to improve awareness about Big Dataanalytics 
- Big data can play a major role in improving the public health care system

- Big data can be better used by providing training to the professionals using it

- Big data can be utilized as follow up tool in the rural development by using data into un specific reports and tools

- Big data can be used for assessing student academic progress, basic facilities in government schools, redeployment $\&$ incentives to teachers

- Big data is being introduced in the Forest Department to manage the huge data uploaded on the servers

- Big data can be used in rural development to gain information about progress and implementation of Rural Development schemes

- Big Data can be used for better data analysis in any sector of government.

- Proper analysis of various data is key to determining the prediction models that could lead to better rainwater management and thereby better cultivation of crops, better disease analysis and its control.

\section{References}

Aggarwal, S (2017). Transforming the Indian Public Delivery system with Big data analytics, Retrieved on 10/10/2018 from www.great learning.in.

Analytics India (2017). The Biggest Big Data Health care trends of health care in 2017. Retrieved on 13.07.2018 from: https://analyticsindiamag.com

Banarjee, A. T., Bandyopadhyay, T., \& Acharya, P. (2013). Data Analytics: Hyped up aspirations or true potetial. Vikalpa, 38(4).

Bhalla, N. (2017). Poor nations need help to use Big data to tackly disease, poverty. Retrieved from Reuters: www.reuters.com on 10/07/2018

Bhattacharya, S. (2017). Drivers and inhibitors of Big Data as a service adoption in India retrieved from https://journals.sagepub.com/doi/abs/10.1177/2394901517696606

Brindley, J. L. (2013). Role of Big data and analytics in developing world. Retrieved from www://accenture.com

Chegus, M. (2017). Big data and Analytics Government organizations, In G. Richareds, Big Data applications in Government; current practises and Future opportunities, CRC Press, Taylor \& Francis group.

Dalai, A. P. (2015). Data Analytics for Rural Development. Indian Journal of Science and Technology, 50-60.

Economic Times (2017). India's challenge is how to use Big data for better governance, Retrieved on 6/10/2018 from http:// economic times.indiatimes.com assess

Elonnai Hickok, S. C. (2014). Big Data in Governance in India: Case Studies, Retrieved from https://cisindia.org/internet-governance/files/Big-data-compilation.pdf.

Elonnani Hickok, S. C. (2017). Big data in Governance in India: Case studies. Banglore: Centre for Internet and Society.

Farahi, A. B. (2017). Research for Evidance. Retrieved from New research on open government data in developing countries: What we can learn from case studies: Retrieved on 10/01/2018 from https://researchforevidence.fhi360.org

Jain, P., Gyanchandani, M., \& Khare, N. (2018). Differencial privacy, its technological perspective using Big Data. Journal of Big Data, 5(15). 
Joshi, N. (2017). Growth of Big Data industry in India. Retrieved on 7/07/2018 from Allerin: http://www.allerin.com

Kshetri, N. (2014). Emerging role of Big Data in key development issues: Opportuniities challenges and concerns. Big data and society.

Maciejewski, M. (2016). To do more, better, faster and more cheaply: Using Big data in Public Administration. International review of Administrative Sciences.

Mayer-Schönberger, V. (2013). Big Data: A revolution that will transform how we live, work, and Think. Retrieved on 07/07/2018 from Vol6-2-BDRAI\%20(2).pdf:

Moorthy, J., Lahiri, R., \& Biswas, N. (2015). Big Data prospects and challenges. Journal of Decision Makers.

Majumdar, J., Naraseeyyappa, S., \& Ankalaki, S. (2017). Analysis of Agriculture data using data mining techniques: Application of Big data. Journal of Big data, 1-15.

Kulkarni, P. (2016). Big data analytics. New Delhi: PHI Learning Private Limited.

Patel, F. (2017). India's growing Big data future. Retrieved on 6/02/2018 from ndtv:https://www.ndtv.com/blog/indias-growing-Big-data-future-1656568

Pavolotsky, J. (2012). Demnestifying Big Data. Business law today, pp. 1-4.

Rani, D. G. (2018). A study about Big data evolution and research challenges. Journal of Information science.

Reddy, D. S. (2014). A survey on the platform for Big Data Analytics, Big Data, 1-20.

Richter, L. T. (2017). The power of smart solutions: Knowledge, Citizenship \& datafication of Banglore's water supply. Banglore: IBM\& Banglore water supply and sewage board.

Roy, A. K. (2017). Big Data and Data Science Iniciatives in India. Biostat, Biometrics journal, Retrieved from.https://juniperpublishers.com/bboaj/pdf/BBOAJ.MS.ID.555561.pdf

Singh, P. (2017). How the Indian Government is using machine learning and Big data for better metrics. Retrieved on 15/08/2018 from https://www.analyticsindiamag.com/indian-government-usingmachine-learning-Big-data-better-metrics/

Sriramaraju, S. (2017). Introduction to Big Data: Infrastructure and networking considerations, Retrieved from Horizon books.com.

SAS (2018). The Power to Know, Retrieved on12/06/2018 from http:/www.sas.com/ NASSCOM. 